\title{
O sujeito volitivo de Schopenhauer como limite do mundo no Tractatus de Wittgenstein
}

\author{
Maygon André Molinari \\ Mestrando em Filosofia pela PUCPR \\ E-mail: maygon.molinari@yahoo.com.br
}

RESUMO: Neste artigo, o sujeito volitivo, vislumbrado em $O$ mundo como vontade e como representação, de Schopenhauer, é relacionado ao sujeito enquanto limite do mundo, no Tractatus Logico-Philosophicus, de Wittgenstein. A partir desta relação, notamos que, não somente a abordagem do sujeito se assemelha, nestes dois filósofos, mas também a abordagem sobre a essência do mundo.

PALAVRAS-CHAVE: Schopenhauer, Wittgenstein, sujeito.

ZUSAMMENFASSUNG: In diesem Artikel, das wollende Subjekt, in Schopenhauers Die Welt als Wille und Vorstellung angedeutet, wird auf das Subjekt als Weltgrenze im Wittgensteins Tractatus Logico-Philosophicus bezogen. Aufgrund dieser Beziehung merken wir, dass sich nicht nur die Subjektthematisierung bei diesen zwei Philosophen ähnelt, sondern auch die Thematisierung der Weltessenz.

SCHLÜSSELWÖRTER: Schopenhauer, Wittgenstein, Subjekt.

\section{Introdução}

Nossa pesquisa busca demonstrar a aproximação entre o Tractatus Logico-Philosophicus, de Ludwig Wittgenstein, e $O$ mundo como vontade e como representação, de Arthur Schopenhauer. Evidente que, sendo a obra de Wittgenstein posterior à de Schopenhauer, notamos a influência deste sobre o autor do Tractatus. A partir de uma noção semelhante de sujeito, as obras mencionadas se aproximam, em um horizonte interpretativo. Tendo por referência tal consideração, analisamos o sujeito como sendo o limite do mundo, no que se refere a não pertencer ao mundo dos fatos (de acordo com a filosofia de Wittgenstein) ou ao mundo da representação (de acordo com a filosofia de

Schopenhauer). Isto quer dizer que não compreendemos o sujeito simplesmente como um ser humano dotado de um corpo físico, por exemplo. Deste modo, nossa pesquisa refere-se a uma análise do chamado sujeito volitivo.

Nesse sentido, nosso trabalho investiga o sujeito pertencente ao que Schopenhauer denominou "o mundo da vontade". Tal sujeito, salientamos, foi denominado por 
Wittgenstein como "metafísico" ou "transcendental". Margutti Pinto observa a relação entre o sujeito transcendental wittgensteiniano e a vontade, no sentido pensado por Schopenhauer:

Wittgenstein $[\ldots]$ identifica o sujeito transcendental com a vontade. Embora o Tractatus não diga com clareza quanto da filosofia schopenhaueriana é ali assumido, podemos pelo menos dizer que se trata da vontade metafisicamente entendida, ou seja, da vontade como limite do mundo, como condição de possibilidade dos fatos e, por isso mesmo, livre das formas próprias aos fatos ${ }^{1}$.

Isto significa que há uma delimitação, e que o sujeito não pertence ao mundo enquanto fato do mundo. Pertence, antes, à esfera da "coisa-em-si". Desta forma, a demarcação do nosso trabalho é dada, por assim dizer, pelos limites do mundo, no sentido de não analisar o sujeito na esfera da representação ou dos fatos.

A influência de Schopenhauer sobre Wittgenstein é bastante evidente ${ }^{2}$. Neste artigo buscamos demonstrar que, ao se analisar a questão do sujeito, efetuamos um percurso em direção ao que seria a essência do mundo. Notamos que tal essência é semelhante nos dois autores, sendo percebida a partir daquilo que Schopenhauer denominou o QUÊ do mundo ${ }^{3}$, e Wittgenstein denominou o Místico ${ }^{4}$.

O percurso deste trabalho, portanto, será o seguinte. Analisaremos o que caracterizaria, na filosofia tractariana, o mundo, e seguiremos até o que seria o seu limite, ou seja, o sujeito. Em seguida, demonstraremos de que maneira o sujeito-limite do Tractatus se assemelha (ou é) o sujeito da obra de Schopenhauer.

\section{Do mundo ao sujeito, no Tractatus}

A ruptura entre mundo e sujeito, percebida no Tractatus Logico-Philosophicus de Wittgenstein, nos remete à relação feita por Schopenhauer entre fenômeno e coisa-em-si,

\footnotetext{
${ }^{1}$ MARGUTTI PINTO, P.R. Iniciação ao silêncio. p. 261.

${ }^{2}$ Acerca da influência de Schopenhauer sobre Wittgenstein, biógrafos e críticos apontaram-na extensamente, como Ray Monk, em $O$ dever do gênio; Paulo Roberto Margutti Pinto, em Iniciação ao silêncio; Marciano Spica, em A religião para além do silêncio, entre outros.

${ }^{3}$ SCHOPENHAUER, A. O mundo como vontade e como representação (doravante, MVR I), § 53, p.357.

${ }^{4}$ Wittgenstein, L. Tractatus Logico-Philosophicus (doravante TLP), p. 279.
} 
ou, mais precisamente, entre representação e vontade. Para compreendermos a referida ruptura tractariana, necessitamos refletir acerca do que caracterizaria, para Wittgenstein, o mundo, e de que maneira esta caracterização conduziria ao sujeito. Nesta abordagem, notamos que a noção schopenhaueriana de sujeito é pertinente para se compreender melhor a obra de Wittgenstein. Por certo não queremos dizer que, sem se compreender Schopenhauer, não se entende o Tractatus, antes, o que pretendemos é apontar para a influência schopenhaueriana sobre Wittgenstein, sobretudo no que se refere à questão do sujeito e da essência do mundo.

Wittgenstein é enfático: "O mundo é a totalidade dos fatos, não das coisas". 5 Esta afirmação significa que é impensável, para Wittgenstein, a existência de objetos isolados, destituídos de qualquer relação, como se estivessem completamente independentes uns dos outros. Para ilustrar esta concepção, basta pensar que não é possível existir um ponto sem um espaço geométrico. Ou seja, não é possível pensar em um objeto sem vinculá-lo a um espaço e também a outros objetos. E a relação, que envolve tanto a espacialidade quanto a existência de outros objetos, representa o que Wittgenstein considera um fato. Neste sentido, dizer o mundo significa dizer os fatos do mundo. Em função disto, Wittgenstein desenvolveu a noção de linguagem figurativa. Tal linguagem se refere a abordar o que existe no mundo, no nível factual, através de proposições. Expressando de outra maneira: dizer o mundo é dizê-lo "propositivamente". Como mencionamos, objetos isolados não constituem o mundo: apenas fatos o constituem.

A noção de linguagem figurativa, portanto, diz respeito à possibilidade de figuração dos fatos do mundo. O que significa que a linguagem, na filosofia do Tractatus, é apresentada como uma imagem do mundo. Dizer é figurar, através de proposições.

No entanto, se as proposições figurativas nos permitem dizer o mundo, não nos permitem dizer o sujeito. Queremos dizer que não nos permitem dizer o sujeito à maneira como dizemos os fatos do mundo, ou como dizemos o mundo da representação. E parece-nos que é quando se insere o sujeito no Tractatus que ocorre, por assim dizer, um início de separação entre o que pode ser dito e aquilo que é inefável. Ora, e de que maneira o sujeito aparece? Para Spica,

\footnotetext{
${ }^{5}$ WITTGENSTEIN, L. TLP, p. 135.
} 
Não há nada no mundo que permita dizer que exista um sujeito. O sujeito é o olho que tudo vê, mas que não pode ver-se a si próprio. Porém que há algo que vê, que representa, mostra-se na linguagem. Ora, é necessário que exista algo que faça as figurações e, este algo é o sujeito volitivo que é condição do mundo e da linguagem ${ }^{6}$.

Ao falarmos apenas do mundo, dos fatos e estados de coisas, não notamos a presença do que poderia ser considerado o sujeito. Não há nada no mundo que permita que se faça esta afirmação. É quando abordamos a questão da figuração que aparece o sujeito considerado por Wittgenstein: "Figuramos os fatos",

Desta forma, o sujeito surge no Tractatus ao figurar o mundo. Wittgenstein nos diz que "a figuração é um fato", , o que significa que figurar é criar fatos. Para Machado, "se, pois, uma figuração é um fato, então afigurar é usar fatos para figurar outros fatos ou estados de coisas" ". Assim, tanto é um fato existir uma árvore que dá frutos, por exemplo, quanto a figuração de que uma árvore dá frutos - logo, a proposição, a sentença. Neste sentido, a proposição é também um fato, e a própria linguagem é um fato do mundo, nesta perspectiva. No entanto, como observamos, o sujeito apontado por Wittgenstein no mundo não se encontra. De que maneira resolver este possível paradoxo?

Wittgenstein diz que o sujeito está para o mundo assim como o olho está para seu campo visual ${ }^{10}$. Nesta perspectiva, de acordo com Margutti Pinto, “assim como o campo visual é sem fim para o olho, o mundo é sem fim para o sujeito" ${ }^{11}$. Logo, é possível pensar que o sujeito não existe, efetivamente, no mundo. Existe, por certo, o corpo de um homem, e existe o olho humano. Mas o olho não é visto por si mesmo, e um corpo, por si só, não é sujeito. Desta forma, podemos considerar que Wittgenstein parte do mundo para chegar ao sujeito.

Alguém poderia pensar que é como se a filosofia wittgensteiniana fizesse um percurso das margens para o centro, como se o sujeito fosse uma figura central. No entanto, o Tractatus nos apresenta o sujeito como uma espécie de figura "marginal", no sentido de que o sujeito não é o centro, mas o limite, a fronteira. Em outras palavras, o sujeito é, por

\footnotetext{
${ }^{6}$ SPICA, M. A. A religião para além do silêncio, p. 51.

${ }^{7}$ WITTGENSTEIN, L. TLP, p. 143.

${ }^{8}$ Idem.

${ }^{9}$ MACHADO, A. N. Lógica e forma de vida, p. 47.

${ }^{10}$ WITTGENSTEIN, L. TLP, p. 247.

11 MARGUTTI PINTO, P. R. Iniciação ao silêncio, p. 261.
} 
essência, excêntrico. Assim, o sujeito não está no mundo, está em (é seu) limite. E de que maneira isto ocorre? Ora, o sujeito que figura os fatos caracteriza o limite do mundo, pois ele não pertence ao nível factual ou da representação. Em outras palavras: o sujeito não é um fato do mundo - o sujeito é quem figura os fatos. Assim, através da figuração, que representa a maneira do sujeito pensar e representar os fatos, o sujeito é compreendido enquanto fronteira ou limite do mundo.

Sendo limite, significa que o sujeito não é o mundo e dele não faz parte, e não é abrigado, portanto, pelas mesmas possibilidades linguísticas de descrição.

Pois, não estando no mundo, não podemos falar do sujeito como falamos de um fato. Pode-se objetar: “Mas não se pode falar - 'um homem usa uma enxada', por exemplo? Ele não é um ‘sujeito', então?” Neste sentido, não. Podemos ver um homem que utiliza uma enxada, e isto constitui um fato, mas esse homem que é afigurado não é um sujeito da maneira como é pensado no Tractatus, que seria o chamado sujeito transcendental ou volitivo.

\section{O sujeito volitivo de Schopenhauer como limite do mundo no Tractatus}

Como notamos, acerca do sujeito tractariano não podemos falar propositivamente, como falamos acerca de um fato do mundo. Por isto, nossa proposta é abordá-lo na perspectiva do sujeito volitivo de Schopenhauer: "Aquele que tudo conhece mas não é conhecido por ninguém é o SUJEITO"12. A perspectiva schopenhaueriana, portanto, parece-nos ser a mesma perspectiva adotada pelo autor do Tractatus. O sujeito conhece o mundo, mas não pode ser conhecido (ao menos não da mesma forma como o mundo é conhecido), por estar em seus limites.

A noção de conhecimento do mundo, em Schopenhauer, não se desvincula da noção de sujeito transcendental ou metafísico. "Torna-se-lhe claro e certo que não conhece sol algum e terra alguma, mas sempre apenas um olho que vê um sol, uma mão que toca uma terra" ${ }^{13}$. Os sentidos não nos oferecem o mundo, apenas uma representação do mundo. O sujeito, assim, sustentáculo não apenas do conhecimento, mas do mundo inteiro, é a

\footnotetext{
12 SCHOPENHAUER, A. MVR I, $\S 2$, p. 45, grifo do autor.

13 SCHOPENHAUER, A. MVR I, § 1, p. 43.
} 
fronteira entre esfera dos fatos e esfera dos valores, entre fenômeno e coisa-em-si, entre representação e vontade.

Podemos dizer que Schopenhauer faz uma ruptura na ruptura kantiana. Ora, se Kant separou fenômeno de coisa-em-si, estabelecendo que esta nos é inalcançável, Schopenhauer nos mostra que a coisa-em-si não somente pode ser alcançada, como é acessível pelo sujeito. Não, evidentemente, da mesma forma como o sujeito acessa o mundo e o conhece. A coisa-em-si é a vontade, e não refere-se à sensação (Empfindung), e sim ao sentimento $(\text { Gefühl })^{14}$.

Deste modo, o que caracteriza de fato o sujeito não pertence à esfera dos nossos sentidos, e da representação que temos através deles. Assim, o sujeito que vê o mundo como representação, é o mesmo que o vive como vontade, por assim dizer. Há uma via de mão dupla: enquanto o sujeito vai em direção ao mundo, vendo-o como fenômeno, o mundo, por sua vez, se apresenta ao sujeito como vontade. Tal via, por certo, significa a simultaneidade do que se dá com o sujeito. Não existe, portanto, uma divisão no tempo. No mesmo instante em que se relaciona com o mundo como fenômeno (representação), relaciona-se também com o mundo como coisa-em-si (vontade). Deste modo, evocando a imagem do limite, ao mesmo tempo em que o sujeito fita, de um horizonte, os fatos do mundo, a essência desse mundo lhe corre nas veias, enquanto vontade.

Esta dupla relação do sujeito, percebida no pensamento schopenhaueriano, enquanto aquele que representa e aquele que vive a vontade, é justamente o que impossibilita, no Tractatus, uma descrição propositiva do sujeito. Assim, não podemos falar, com proposições passíveis de verdade ou falsidade, de nenhum sujeito, embora possamos descrever que um homem usa uma enxada, como notamos no exemplo. Em outras palavras: não se fala do sujeito como se fala, por exemplo, que a água ferve a $100^{\circ} \mathrm{C}$. A esfera do sujeito, em não sendo a mesma dos fatos, não possibilita uma verificação científica.

Neste sentido, o lado do sujeito que não conhecemos através dos sentidos, ou seja, o mundo do sujeito volitivo, que abriga os valores, tanto estéticos quanto éticos e religiosos, estaria, portanto, fora do mundo: “[...] o sujeito transcendental não se encontra no mundo, mas é limite dele. Assim, embora não pertençam ao mundo como conjunto de fatos, os valores pertencem ao sujeito transcendental como limite do mundo"15. Esta consideração

${ }_{14}^{14}$ SCHOPENHAUER, A. MVR I, $\S 1$, p.101.

${ }^{15}$ MARGUTTI PINTO, P. R. Iniciação ao silêncio, p. 236. 
diferencia aquilo que pertence ao sujeito volitivo (esfera da vontade) daquilo que pertence ao mundo dos fatos (esfera da representação). Deste modo, se as esferas são distintas, não podem ser analisadas da mesma maneira. Até porque, “[...] nossa vida, enquanto fato do mundo, é totalmente arbitrária; enquanto contemplada pelo sujeito transcendental, possui um significado ético necessário""16.

Sendo assim, o sentido da vida e do mundo só pode ser conferido pelo sujeito, que justamente está nos limites do mundo: "O sentido do mundo deve estar fora dele. No mundo, tudo é como é e tudo acontece como acontece; não há nele nenhum valor - e se houvesse, não teria nenhum valor"17.

Logo, não há valor nos fatos, considerados por si mesmos. Em outras palavras: não há valor algum no fenômeno. Evidente, pois a valoração está no sujeito que atribui valor a um fato.

Deste modo, “é próprio do sujeito volitivo perguntar-se sobre o que do mundo e da vida. É a vontade do sujeito que procura pelo sentido do mundo". ${ }^{18}$ Se isto é verdade, a vontade do sujeito é, também, uma vontade de sentido. Como o sentido não existe no mundo, o sujeito, então, confere um significado aos fatos.

É como se a vida e o mundo impusessem ao sujeito uma espécie de dever, no que se refere a atribuir um sentido a ambos, que justifique, ou busque justificar, de alguma forma, sua existência como sujeito.

A questão do sentido do mundo, como se pode depreender desta interpretação, está vinculada à questão dos valores. Pois, da mesma forma como os valores não se encontram no mundo, não se encontra nele o seu próprio sentido. Ora, significaria dizer que não existe valor algum no mundo, de acordo com Wittgenstein? Exatamente. Repudiamos um assassinato, no entanto, o motivo do repúdio está contido em nós, em nossa cultura, e não no assassinato de um homem, na ação em si mesma. Como afirma Barret, "a bondade ou maldade da ação está fora da ação" ${ }^{\text {"19 }}$.

Deste modo, não podemos dizer um valor, porque não podemos aplicar a ele a linguagem figurativa. Percebemos melhor esta concepção na seguinte afirmação de Spica:

\footnotetext{
16 Idem.

17 WITTGENSTEIN, L. TLP, p. 275.

18 SPICA, M. A. A religião para além do silêncio, p. 82.

19 BARRET, C. Ética y creencia religiosa en Wittgenstein, p. 62, grifo do autor.
} 
Tudo o que pode ser dito está reduzido ao campo da linguagem figurativa. Assim, só têm sentido as proposições que representam o mundo. Neste só há fatos e na linguagem com sentido só há proposições que figuram os fatos. 'Proposições filosóficas' não figuram o mundo, como tal, não têm sentido. Da mesma forma, 'proposições' da ética, da estética e da religião não figuram o mundo. Portanto, elas não podem ser ditas. Elas tratam do que possui valor e no mundo nada possui valor ${ }^{20}$.

Seria como dizer que no mundo da representação não existem valores, pois as coisas apenas nos chegam pelos sentidos, não portando verdade ou mentira, bondade ou maldade.

A partir desta constatação, nos parece evidente a reflexão de Wittgenstein acerca do “eu filosófico", quando o distingue do corpo humano: "o eu filosófico não é o homem, não é o corpo humano, ou a alma humana, de que trata a psicologia, mas o sujeito metafísico, o limite $[\ldots]$ do mundo" 21 .

Assim, o corpo de um homem não caracteriza, por si só, o sujeito, pois o corpo é objetivo e pertence ao mundo dos fatos ou da representação. A este respeito, Schopenhauer nos esclarece: “O sujeito que conhece é indivíduo exatamente em sua referência especial a um corpo que, considerado fora de tal referência, é apenas uma representação igual a qualquer outra" ${ }^{22}$. Neste sentido, o acesso do sujeito ao mundo, através de seu corpo, pressupõe que, aquilo mesmo que permite que se conheça o mundo, existe igualmente como representação. É como se, para um determinado objetivo, nos servíssemos, de alguma forma, desse mesmo objetivo. Como se para quebrar uma pedra utilizássemos instrumentos feitos também de pedra. E a vontade, neste caso, seria a força a segurar e a mover o instrumento. Para Vilmar Debona, “o que permite o conhecer do sujeito, nesse processo de formação das intuições empíricas, é o próprio corpo do indivíduo"23. Assim, o corpo é o intermediário entre o sujeito e o mundo. Uma espécie de ponte, sobre a qual se move o conhecimento, ponte que de alguma forma mantém o sujeito separado do mundo, ou que o torna, nas palavras de Wittgenstein, o limite do mundo.

$\mathrm{O}$ aparente isolamento do sujeito não o torna, no entanto, alheio ao mundo e incapacitado para relacionar-se. Estar nos limites do mundo não significa impossibilidade ética ou moral, por exemplo, até porque, a ética e a moral pertencem, não ao mundo dos

\footnotetext{
${ }^{20}$ SPICA, M. A. A religião para além do silêncio, p. 36.

21 WITTGENSTEIN, L. TLP, p. 247.

22 SCHOPENHAUER, A. MVR I, § 19, p. 161.

23 DEBONA, V. Schopenhauer e as formas da razão, p. 37.
} 
fatos ou da representação, mas ao mundo do sujeito e da vontade. Na vontade se situa o significado ético e moral do mundo.

Evidente que parece haver um paradoxo, quando dizemos (na perspectiva de Wittgenstein) que o sujeito não pertence ao mundo, e quando relacionamos esta afirmação à perspectiva schopenhaueriana, que nos diz que o mundo existe como representação e como vontade. Ora, este paradoxo é apenas aparente, senão, vejamos. Conceber o sujeito como limite implica compreender que o mundo factual (da representação) é acessível pelos sentidos, enquanto o mundo do sujeito volitivo, onde localizam-se os valores e as ações, não pode ser acessado da mesma forma. Em outras palavras: a vontade não nos é alcançável pela sensação (Empfindung).

Não há divergência, portanto, na abordagem wittgensteiniana e na abordagem de Schopenhauer. De qualquer forma, o sujeito e a vontade estão fora do mundo da representação. A coisa-em-si, para Schopenhauer, não se situa (evidentemente!) no nível fenomenal. Em outras palavras: a vontade não é abordada como o são os fenômenos - o mundo do sujeito volitivo não pode ser dito propositivamente, como são ditos os fatos do mundo.

\section{3. $O$ fim da escada}

Nossa insistência, neste trabalho, em falar da linguagem figurativa do Tractatus, visava, assim, atingir aquilo que está além da proposição, e que Wittgenstein considerou o inefável.

$\mathrm{Na}$ filosofia tractariana, aquilo que está fora do mundo não pode ser dito propositivamente. "Sobre aquilo de que não se pode falar, deve-se calar" 24 , assevera o último aforismo do Tractatus Logico-Philosophicus. Por certo isto não significa o fim da linguagem, ou um silêncio absoluto sobre questões de valor. Significa que sobre questões valorativas não se pode falar com pretensões de verdade, como se fala a respeito de um fato do mundo. Ora, aqui temos o que Wittgenstein considerou o Místico, o 'fim da escada'. Ao atingir-se o limite do mundo, ou seja, ao chegar à esfera do sujeito volitivo, do sujeito que valora, e assim ultrapassar a condição factual do mundo, chega-se ao Místico. E "o Místico

$\overline{{ }^{24} \text { WITTGENSTEIN, L. TLP, p. } 281 .}$ 
não é como o mundo é, mas que ele é"25. E não estará nesta consideração de Wittgenstein a conexão mais profunda com a obra de Schopenhauer? Ora, para este

O autêntico modo de consideração filosófico do mundo, ou seja, aquele que nos ensina a conhecer a sua essência íntima e, dessa maneira, nos conduz para além do fenômeno, é exatamente aquele que não pergunta "de onde", "para onde", "por que", mas sempre e em toda parte pergunta pelo QUÊ do mundo, vale dizer, não considera as coisas de acordo com alguma relação $[\ldots]^{26}$.

E o 'quê' não se refere ao nível factual. Não se refere a descrições ou perguntas teleológicas. Sendo desta forma, o "quê" do mundo, que faz com que este seja assim e não de outro modo, é um dos elementos que unem intimamente o Tractatus a'O Mundo como vontade e como representação.

Apesar de Wittgenstein percorrer um caminho, em alguns momentos, (aparentemente, talvez) diverso do percorrido por Schopenhauer, sua percepção do 'que' do mundo une os dois pensadores no que se refere a atingir a essência do mundo, ou seja, aquilo que caracterizaria, no Tractatus, o fim da escada, aquilo que está além dos fatos e da representação.

\section{Conclusão}

O objetivo deste trabalho foi relacionar o sujeito-limite, do Tractatus, ao sujeito volitivo de Schopenhauer. E, se dissemos que Schopenhauer fez uma ruptura na ruptura kantiana, podemos conjecturar que Wittgenstein aprofundou tal fenda. Isto significa que tanto Schopenhauer quanto Wittgenstein consideraram que existe um limite entre o mundo da representação, ou dos fatos, e o mundo da vontade, ou a esfera do sujeito volitivo. Ora, a consideração deste limite representa uma distinção na forma de se utilizar a linguagem para descrever o mundo e o sujeito. Não é possível, portanto, falar da esfera volitiva como se fala da esfera fenomênica. Como observamos, Schopenhauer enfatizou que o sujeito que conhece não pode ser conhecido. Ora, aqui ele não está dizendo que o sujeito é inacessível

\footnotetext{
${ }^{25}$ WITTGENSTEIN, L. TLP, p. 279.

${ }^{26}$ SCHOPENHAUER, A. MVR I, § 53, p. 357.
} 
e que seria algo ilusório. Ao contrário, o que Schopenhauer faz é elucidar que o sujeito pertence ao mundo da vontade, e não da representação.

Da mesma forma, Wittgenstein não trata o sujeito como uma ficção, pelo fato de não pertencer à esfera dos fatos. Enquanto limite do mundo, o sujeito representa para Wittgenstein a possibilidade de ação ética. Em outras palavras, como notamos, no sujeito encontra-se a valoração, tendo-se considerado que no mundo não existem valores, apenas fatos.

Observamos que tanto Schopenhauer quanto Wittgenstein se movem num espaço em que a linguagem, por sua própria natureza, pode apontar, mas não se revela capaz de compor uma descrição suficiente, em relação ao sujeito e àquilo que pertence à sua esfera. Como afirmou Wittgenstein: “Os limites de minha linguagem significam os limites do meu mundo"27. Tal afirmação nos remete a uma constatação importante, acerca dos dois filósofos: a divisão entre fenômeno e coisa-em-si se dá através do sujeito, que tanto experimenta o mundo como vontade, como o percebe enquanto representação.

Desta forma, se não é possível abordar o sujeito volitivo como são abordados os fatos do mundo, consideramos que a noção de inefável, advinda da filosofia de Wittgenstein, nos revela que o silêncio não representa uma falta de conhecimento, mas a condição limítrofe do sujeito, ou, dizendo de outro modo, a condição do sujeito-limite do mundo.

\section{Referências}

BARBOZA, Jair. Schopenhauer: A decifração do enigma do mundo. São Paulo: Moderna, 1997.

BARRETT, Cyril. Ética y creencia religiosa en Wittgenstein. Trad. Humberto M. González. Madrid: Alianza Editorial, 1994.

DEBONA, Vilmar. Schopenhauer e as formas da razão: o teórico, o prático e o ético-místico. São Paulo: Annablume, 2010.

KANT, Immanuel. Crítica da Razão Pura. Trad. de Valério Rohden e Udo Baldur Moosburger. São Paulo: Abril Cultural, 1980. (Os Pensadores)

MARGUTTI PINTO, Paulo Roberto. Iniciação ao Silêncio. Análise do Tractatus de Wittgenstein. São Paulo: Edições Loyola, 1998.

\footnotetext{
${ }^{27}$ WITTGENSTEIN, L. TLP, p. 245.
} 
MONK, Ray. Wittgenstein: o dever do gênio. Trad. de Carlos Afonso Malferrari. São Paulo: Companhia das Letras, 1995.

SCHOPENHAUER, Arthur. O mundo como vontade e como representação. Tomo I; tradução, apresentação, notas e índices de Jair Barboza. São Paulo: Editora UNESP, 2005.

SPICA, Marciano Adilio. A religião para além do silêncio. Curitiba: CRV, 2011.

VALLE, Bortolo. Wittgenstein: A forma do silêncio e a forma da palavra. Curitiba: Champagnat, 2003.

WITTGENSTEIN, Ludwig. Tractatus Logico-Philosophicus. Trad. Luiz Henrique Lopes dos Santos. São Paulo: Editora da Universidade de São Paulo, 2001.

. Culture and Value. Oxford: B. Blackwell, 1984.

Recebido: $10 / 12 / 12$

Received: $12 / 10 / 12$

Aprovado: 31/01/12

Approved: 01/31/12 